\title{
IN VITRO EVALUATION OF BONDING DURABILITY OF CEMENT- RETAINED IMPLANT-SUPPORTED RESTORATIONS USING THREE DIFFERENT INTERIM LUTING AGENTS
}

\author{
Mohamed Ramadan*, Mahmoud Shakal * and Waleed Elshahawy *
}

\begin{abstract}
Purpose: The main disadvantage of cement-retained implant restorations is their difficulty in retrievability. Therefore, retrievability of the restoration can be maintained if provisional cement is used. The aim of this study is to evaluate bond strength durability of cement retained implantsupported restorations using three different interim luting agents in-an in vitro condition.

Materials and Methods: Sixty standard titanium abutments were tightened to implant analogs. The implant-abutment complex was embedded vertically in auto-polymerizing acrylic resin block. Metal copings with a loop on the occlusal surface were fabricated using nickel chromium $(\mathrm{Ni}-\mathrm{Cr})$ alloy. The copings were luted using provisional cement. According to type of cement, specimens were equally divided into three groups: Provilat calcium hydroxide cement (group A), Rely x Temp NE (group B), Cavex temp NE (group C). Each group was equally sub-divided into two subgroups according to storage condition before tensile testing: subgroup 1: specimens were stored in distilled water for 24 hours at $37^{\circ} \mathrm{C}$, subgroup 2: specimens were stored as subgroup 1 and then subjected to thermocycling and mechanical loading $\left(5000\right.$ cycle, $5-55^{\circ} \mathrm{C}, 30-\mathrm{s}$ dwell time, $20 \mathrm{~s}$ transfer time). Specimens were tested for tensile bond strength using universal testing machine at across head speed of $0.5 \mathrm{~mm} / \mathrm{min}$. Tensile failure of the copings were recorded in Newton. Samples were examined under digital microscope to detect the mode of failure. Results were statistically analyzed by ANOVA test $(\mathrm{P}<0.05)$.
\end{abstract}

Results: For short-term water storage, cement failure loads of subgroups A1, B1 and C1 were $112.9 \pm 27.2,54.6 \pm 13.2$ and $58.6 \pm 20.8 \mathrm{~N}$, respectively. Subjecting the specimens to short-term water storage in addition to thermocycling and mechanical loading corresponding to 6 month of clinical use has led to significant loss of retentive values (subgroups A2, B2 and C2 were 74.1 \pm 18.2 , $52.4 \pm 24.6$ and $46.5 \pm 18.3 \mathrm{~N}$, respectively).

Conclusions: Provilat cement has the best retention results. Calcium hydroxide based provisional luting agent seems to be more appropriate for the cementation of implant supported restoration, if retrievability is important

KEYWORD: Implants, Titanium abutment, Luting cement, Tensile bonding.

* Department of Fixed Prosthodontics, Faculty of Dentistry, Tanta University 


\section{INTRODUCTION}

Implant retained prostheses have become a wellestablished option for treatment of the partially or fully edentulous patient and often represent an improvement over traditional alternativeness ${ }^{[1]}$. The implant-supported prosthesis is attached to implant abutments either by cementation, or by retaining screws. Because of the advantages of cementretained implant-supported restorations, such as passive fit, ease of fabrication, superior esthetics, fewer components, and uncomplicated laboratory technique, these restorations have gained popularity compared to screw-retained restorations ${ }^{[2]}$.

Retrievability may be a critical aspect of implantsupported restorations because of problems such as mechanical failures, treatment of peri-implant tissues and evaluation of implants mobility ${ }^{[3]}$. Permanent luting agents are too retentive and may damage the osseointegration of the implant during removal of the restorations ${ }^{[4]}$. In addition, a crown cemented to an implant abutment may be difficult, if not impossible, to retrieve without sectioning it, thus destroying the restoration and adding cost and time to renewal ${ }^{[5]}$. Therefore, interim cements have been recommended for restorations that may require intervention.

The issue of expressing potentially irretrievable excess cement on seating crowns is also a complication for cement-retained types ${ }^{[6]}$. In most instances, surgery was required to remove excess cement. In a study of cement removal from restorations permanently luted to titanium abutments with simulated subgingival margins, resin cement was proven to be the most difficult to remove when excess was expelled subgingivally ${ }^{[7]}$. The use of temporary cements has been promoted as excess extruded cement may dissolve within a short period of time, however, not all temporary cements may dissolve rapidly particularly when located subgingivally ${ }^{[8]}$.
In considering cement-retained implant-supported prosthesis, the ideal cement should be strong enough to retain the crown indefinitely, yet weak enough to allow the clinician to retrieve it if necessary. However, it is difficult to quantify retention values that provide this ideal. It should be borne in mind that variables such as abutment taper, cervico- occlusal wall height, surface finish of the abutment and casting have an important influential effect on crown retention. In addition, the type of cement used and seating pressure affect cement properties and performance and hence crown retention ${ }^{[2,4]}$. It is important to be aware of the retentive properties of the chosen cement.

The use of different cements, protocols, and implant systems may alter the retentive strength of implant-supported restorations. In addition, different aging processes, such as thermal cycling and mechanical loading can also affect the retentive strength ${ }^{[9]}$. Unfortunately, little data are available for the cement failure loads of provisional luting agents used for the cementation of fixed prostheses supported by implants after thermal cycling and mechanical loading. Therefore, the aim of this study is to evaluate bonding durability of cement retained implant-supported restorations using three different interim luting agents in-an in vitro condition.

\section{MATERIALS AND METHODS}

\section{Selection of specimens}

Sixty standard titanium abutments* with $5.5 \mathrm{~mm}$ length beginning from the top of the abutment to the finish line (chamfer finish line), $3.5 \mathrm{~mm}$ diameter and $5^{\circ}$ taper were used in the study. Anti rotational abutments with one flat surface were selected to avoid coping rotation on the abutment during cementation process ${ }^{[10,11]}$. Sixty implant analogs* with $12 \mathrm{~mm}$ length and $3.5 \mathrm{~mm}$ diameter were used.

\footnotetext{
* TUT Dental implant system, Cairo, Egypt
} 


\section{Preparation of specimens}

Each abutment was attached to an implant labanalog using screw driver only. Specimens were embedded vertically in special specimen holders (rings) that were filled with auto polymerizing acrylic resin* using dental laser beam surveyor**. The resin has a modulus of elasticity of approximately $1.6 \mathrm{Gpa}$ which approximates that of human cancellous bone (0.49Gpa) ${ }^{[12]}$. All abutments screw access channels were filled with compacted cotton pellet and sealed flush with the occlusal surface with composite $\operatorname{resin}^{[13]}$.

\section{Coping fabrication}

Abutments were coated by double layer of die spacer*** using a fine brush covering the whole length leaving only $0.5 \mathrm{~mm}$ before the finish line without die spacer to allow precise marginal fit of the suprastructure on the abutment. According to manufacture instruction, each painting of the die spacer provided a space of $15 \mu \mathrm{m}$. So, a $30 \mu \mathrm{m}$ space was provided by making two paintings on each abutment ${ }^{[14,15,16]}$.

The wax-up was designed using melted inlay wax $^{* * * *}$ in thickness of $0.5 \mathrm{~mm}$. Also, a loop of wax ( $2.5 \mathrm{~mm}$ wide and $5 \mathrm{~mm}$ diameter) were added to the occlusal surface of each coping for attachment to the tensile testing device and was centered using dental surveyor ${ }^{* *}[17]$.

The wax patterns were sprued $(2 \mathrm{~mm}$ in diameter and $10 \mathrm{~mm}$ in length). Investing was carried out with a phosphate-bonded investment ${ }^{* * * * *}$. A $100 \mathrm{mg}$ investment material was mixed with colloidal silica liquid and subsequently the investment ring was carefully filled. After 30 minutes of setting time, the investing ring was preheated at $200^{\circ} \mathrm{C}$ in a furnace and was held in this temperature for 30 minutes. Most of the wax was eliminated by this way. After that, the heat was increased to the final burnout temperature $850^{\circ} \mathrm{C}$ and was held for 45 minutes ${ }^{[17]}$. The invested wax pattern was casted using a nickel-chromium alloy ${ }^{7}$. Thickness of the metal copings was measured with a digital caliber to make sure that it had thickness of $0.5 \mathrm{~mm}$. Stability of the coping was assessed by applying finger pressure vertically to the coping during seating on the abutment and considered acceptable if the crown did not have any rotational movement on the abutment ${ }^{[18]}$. Finally, the intaglio of all copings were air abraded with $250 \mu \mathrm{m}$ aluminum oxide particles at a pressure of 2 bars, from a $5 \mathrm{~mm}$ distance for 1 minute and dried with compressed air before initial testing. All defective castings were excluded from study ${ }^{[19]}$. Each casting was randomly numbered and paired with an implant-abutment assembly for further procedures.

\section{Distribution of specimens}

The sixty specimens were distributed according to the type of cement used into three groups ( $\mathrm{n}=$ 20): Provilat calcium hydroxide cement (group A), RelyX Temp NE (group B), Cavex temp NE (group C). The cements tested are listed in Table 1. Each group was further subdivided into two subgroups $(n=10)$ according to storage condition before tensile testing.

In subgroup 1, specimens were subjected to tensile testing after storage in distilled water for 24 hours at $37^{\circ} \mathrm{C}$. In subgroup 2, specimens were stored in distilled water at $37^{\circ} \mathrm{C}$ for 24 hours and then subjected to thermocycling for 5000 cycles at $5-55^{\circ} \mathrm{C}$ with a 30 s dwell time and 20 seconds transfer time.

\footnotetext{
* Acrostone acrylic resin, Acrostone Manufacturing Co., Cairo, Egypt

** Ramses Medical Products Co., Cairo, Egypt

*** Die spacer, Kerr, Bioggio, Switzerland

***** Yeti Carving wax, Keystone Industries GmbH, Singen, Germany

***** Bellavest SH, Bego, Bremen, Germany

******* Meta 4all, Ivoclar-Vivadent, Schaan, Liechtenstein
} 
TABLE (1) Tested luting cements.

\begin{tabular}{|l|l|l|}
\hline \multicolumn{1}{|c|}{ Material } & \multicolumn{1}{c|}{ Manufacturer } & \multicolumn{1}{c|}{ Product } \\
\hline Calcium hydroxide cement & Promedica, Neumunster, Germany & Provilat cement. \\
\hline Zinc oxide non-eugenol temporary cement & 3MEspe, Neuss,Germany & Rely X temp Cement. \\
\hline Zinc oxide non-eugenol temporary cement & Cavex,Haarlem, Holland & Cavex temp cement. \\
\hline
\end{tabular}

\section{Cementation procedures:}

The cementation was done in accordance with the manufacturer's instructions for mixing time, mixing conditions and cement component ratios. All cements were mixed and all crown copings cemented by the same operator. Luting agent was applied to completely cover all internal walls of the copings, and then copings were seated onto abutments with firm finger pressure for 10 seconds, followed by a $3 \mathrm{~kg}$ axial compressive load for 10 minutes using custom-made tightening device. Excess cement was removed using an explorer. Specimens were examined visually to confirm complete seating of the coping onto the abutment, referenced by marginal integrity and the absence of marginal space ${ }^{[20]}$.

\section{Short term water storage}

It was done for all six subgroups (A1, B1, C1, A2, B2, C2). Immediately after cementation, specimens were stored in distilled water at $37^{\circ} \mathrm{C}$ for 24 hours using water bath system* before tensile testing procedures.

\section{Tthermocycling}

It was only done for three subgroups (A2, B2, C2). The specimens were subjected to thermocycling for 5000 cycles at $5-55^{\circ} \mathrm{C}$ with a 30 -s dwell time and 20 seconds transfer time after the water stor- age. This is corresponding to six months of clinical condition ${ }^{[13]}$.

\section{Cyclic loading}

The thermocycled specimens were subjected to cyclic loading which corresponds to six months of clinical condition ${ }^{[21]}$ Specimens were individually and vertically mounted in the lower fixed compartment of a computer controlled materials testing machine ${ }^{* *}$ with a load cell of 10 $\mathrm{kg}$. Data were recorded using computer software (Bluehill Lite, Instron Instruments). The specimens underwent pre-loading in a cyclic manner. Each sample underwent 120.000 cycles at load cell of $10 \mathrm{Kg}$ with a load profile in the form of a sine wave at frequency of $1.7 \mathrm{~Hz}$ The rate was used as equivalent to the average masticatory cycle of 0.8 $1.0 \mathrm{~s}$ i.e. clinically relevant ${ }^{[22]}$. Force was applied with a custom made load applicator [steel rod with flat tip (20x25mm) placed occlusally] attached to the upper movable compartment of the machine.

\section{Tensile testing}

The entire samples were secured to the holding device of the universal loading ${ }^{* * *}$. Each implantblock complex embedded with its own cemented crown was secured with tightening screws to the lower fixed compartment of a materials testing machine $^{* * * *}$ with a load cell of $10 \mathrm{kN}$. The occlusal

\footnotetext{
* Whip-mix Corp., Louisville, KY, USA

** Model 3345, Instron Instruments Ltd., Norwood, MA, USA

*** Lloyd 30k, Lloyd instruments ltd., Segensworth, UK.

**** Model LRX-plus; Lloyd Instruments Ltd., Segensworth, UK
} 
loops of specimens were hooked into the upper movable compartment of the testing machine. The tensile load with pull out mode of force was applied at a crosshead speed of $0.5 \mathrm{~mm} / \mathrm{min}$ and parallel to the longitudinal axis of the specimens. The load required for dislodgement was recorded in Newtons. The failure mode was recorded after dislodgement of the copings. Data was recorded using computer software (Nexygen version 4.0).

\section{Scanning digital-microscope}

After dislodgment of the metal copings implant abutments. All samples were examined under digital microscope. The abutments with their acrylic blocks were positioned perpendicular under a digital-microscope by using costume made holding device*, magnification X 50, and the images were captured and transferred to IBM personal computer equipped with the image tool software (Image J1.43U, National Institute of Health, USA).

\section{Statistical Analysis}

The collected data were organized, tabulated and statistically analyzed using SPSS software statistical computer package version 17 . One way ANOVA was used to compare between subgroups. Two-way ANOVA was used to study the effect of thermodynamic cycling on the retention. Post Hoc test "Least Significant Difference (LSD)" were used for multiple comparisons within groups.

\section{RESULTS}

\section{Short term water storage}

It was observed that all specimens bonded with all three tested cements showed adhesive form of failure. Islands of cement attached to the transverses grooves of the abutments have been detected. Cement remnants adhered to internal fitting surface of the copings have been also detected.

\footnotetext{
* Scope Capture Digital Microscope, Guangdong, China

Descriptive statistics of tensile test results for all groups are presented in Table 2. There were differences in cement failure loads among the various cements tested. Provilat calcium hydroxide cement (subgroup A1) had the highest cement failure load (subgroup A1=112.9 $\pm 27.2 \mathrm{~N}$ ) while RelyX Temp NE (subgroupB1) had the lowest cement failure load (subgroup B1=54.6 $\pm 13.2 \mathrm{~N}$ ). Even though, there was no significant difference between $\mathrm{Re}$ lyX Temp NE and Cavex Temp NE (subgroup C1) (subgroup C1=58.6 $\pm 20.8 \mathrm{~N}$ ).

The results of one-way ANOVA analysis were presented in Table 3. A statistically significant difference $(F=23.5, p)$ between different studied group occur as regard tensile bond strength. Least Square Difference (LSD) Post Hoc test (Table 4) showed a significant differences $(\mathrm{p}=0.000<0.05)$ for tensile bond strength between Provilat cement group and Rely $x$ Temp NE cement. Provilat cement has significant higher bonding value than that of Rely x Temp NE cement. In addition, a significant difference $(p=0.000<0.05)$ was found between Provilat cement group and Cavex Temp NE cement group. Provilat cement has significant higher bonding value than that of Cavex Temp NE cement. There was no statistically significant difference in tensile bond strength between Rely x Temp NE and Cavex Temp NE $(p=0.676>0.05)$.

\section{Short term water storage and thermodynamic stressing}

Thermal and mechanical stressing of the specimens has only change the bonding values (i.e. cement failure load), but did not change the mode failure for all three cements. There was an adhesive form of failure because complete wash out of cements from the smooth surface of the abutments have been detected in addition to partial wash out of cements from the internal surfaces of the copings. 
Descriptive statistics of tensile test results for all groups are presented in Table 5. There were differences in cement failure loads among the various cements tested. Provilat calcium hydroxide cement (subgroup A2) had the highest cement failure load $(74.1 \pm 18.2 \mathrm{~N}$ ) while Cavex Temp NE (subgroup C2) had the lowest cement failure load $(46.5 \pm 18.3$ $\mathrm{N})$. Even though, there was no significant difference between Cavex Temp NE and Rely x Temp NE (subgroup B2 = 52.4 \pm 24.6 ).

The results of one-way ANOVA analysis were presented in Table 6. A statistically significant difference $(F=5.018, p)$ between different studied group occur as regard tensile bond strength. Least Square Difference (LSD) Post Hoc test (Table 7) showed a significant differences $(p=0.025<0.05)$ for tensile bond strength between Provilat cement and Rely x Temp NE after subjected to thermo-cycling and cyclic loading tests. Provilat cement has significant higher bonding value than that of Rely $\mathrm{x}$ Temp NE cement. In addition, a significant difference ( $p=0.006<0.05)$ was found between Provilat cement group and Cavex Temp NE cement group. Provilat cement has significant higher bonding value than that of Cavex Temp NE cement. There was no statistically significant difference in tensile bond strength between Rely x Temp NE and Cavex Temp $\mathrm{NE}$ after subjected to thermo-cycling and cyclic loading test $(\mathrm{p}=0.528>0.05)$.

\section{Effect of thermal cycling on retention}

Regardless of the cement type, two-way ANOVA analysis revealed that non-thermocycled groups recorded statistically significant $(\mathrm{F}=14.27 \mathrm{p}<0.05)$ higher surface retention values than thermocycled groups as shown in Figure 1.

TABLE (2) Sample size, mean, standard deviation, minimum, and maximum of the cement failure loads for the different cements after short-term water storage.

\begin{tabular}{|c|c|c|c|c|c|c|c|c|}
\hline & $\mathbf{N}$ & Mean (N) & $\begin{array}{c}\text { Std. } \\
\text { Deviation }\end{array}$ & Std. Error & \multicolumn{2}{|c|}{$\begin{array}{c}\text { 95\%fidence Interval } \\
\text { for Mean }\end{array}$} & Minimum & Maximum \\
\hline $\begin{array}{c}\text { A1 } \\
\text { Provilat }\end{array}$ & 10 & 112.9 & 27.2 & 8.6 & 93.5 & 132.3 & 67.6 & 160.1 \\
\hline $\begin{array}{c}\text { B1 } \\
\text { RelyX }\end{array}$ & 10 & 54.6 & 13.2 & 4,19 & 45.1 & 64.1 & 23.4 & 67.6 \\
\hline $\begin{array}{c}\text { C1 } \\
\text { Cavex }\end{array}$ & 10 & 58.6 & 20.8 & 6,59 & 43.7 & 73.5 & 38.1 & 96.5 \\
\hline Total & 30 & 75.4 & 33.9 & 6.2 & 62.7 & 88.0 & 23.4 & 160.2 \\
\hline
\end{tabular}

Table 3: Comparison between the different studied groups as regard the tensile bond strength using one way ANOVA test after short-term water storage.

\begin{tabular}{|c|c|c|c|c|c|}
\hline & Sum of Squares & Df & Mean Square & F & Sig. \\
\hline Between Groups & 21196.224 & 2 & 10598.112 & 23.571 & $* .000$ \\
\hline Within Groups & 12140.061 & 27 & 449.632 & & \\
\hline Total & 33336.285 & 29 & & & \\
\hline
\end{tabular}

* Significant difference at $p<0.05 \%$ 
TABLE (4) Comparison between different studied groups as regard tensile bond strength using Post Hoc test (LSD) after short-term water storage

\begin{tabular}{|c|c|c|c|c|c|c|}
\hline \multirow{2}{*}{ (I) Factor } & $(J)$ Factor & $\begin{array}{c}\text { Mean Difference } \\
(I-J)\end{array}$ & Std. Error & \multicolumn{2}{|c|}{ Sig. } & \multicolumn{2}{|c|}{ 95\% Confidence Interval } \\
\hline \multirow{2}{*}{ Provilat cement } & Rely x Temp & 58.2817 & 9.4830 & $.000\left(^{*}\right)$ & 38.8243 & 77.7391 \\
\cline { 2 - 7 } & Cavex Temp & 54.2778 & 9.4830 & $.000\left(^{*}\right)$ & 34.8203 & 73.7352 \\
\hline \multirow{2}{*}{ Rely x Temp } & Provilat cement & 58.2817 & 9.4830 & $.000\left(^{*}\right)$ & -77.7391 & -38.8243 \\
\cline { 2 - 7 } & Cavex Temp & 4.0040 & 9.4830 & .676 & -23.4613 & 15.4534 \\
\hline \multirow{2}{*}{ Cavex Temp } & Provilat cement & 54.2778 & 9.4830 & $.000\left(^{*}\right)$ & -73.7351 & -34.8203 \\
\cline { 2 - 7 } & Rely x Temp & 4.0040 & 9.4830 & .676 & -15.4534 & 23.4614 \\
\hline
\end{tabular}

* Significant difference at $p<.05 \%$.

TABLE (5) Sample size, mean, standard deviation, minimum, and maximum of the cement failure load for the different cements after short-term water storage and thermo-dynamic stressing.

\begin{tabular}{|c|c|c|c|c|c|c|c|c|}
\hline & $\mathbf{N}$ & Mean & Std. Deviation & Std. Error & $\begin{array}{c}\text { 95\% Confidence Interval } \\
\text { for Mean }\end{array}$ & Minimum & Maximum \\
\hline $\begin{array}{c}\text { A2 } \\
\text { Provilat }\end{array}$ & 10 & 74.1 & 18.2 & 5.75764 & 61.12 & 87.17 & 45.7359 & 96.74175 \\
\hline $\begin{array}{c}\text { B2 } \\
\text { RelyX }\end{array}$ & 10 & 52.4 & 24.6 & 7.77453 & 34.78 & 69.95 & 11.7076 & 90.47290 \\
\hline $\begin{array}{c}\text { C2 } \\
\text { Cavex }\end{array}$ & 10 & 46.5 & 18.3 & 5.77987 & 33.40 & 59.55 & 16.5609 & 72.92033 \\
\hline Total & 30 & 57.67 & 23.25 & 4.24521 & 48.98 & 66.35 & 11.7076 & 96.74175 \\
\hline
\end{tabular}

TABLE (6) Comparison between the different studied groups as regard the tensile bond strength using one way ANOVA test after short-term water storage and thermo-dynamic stressing.

\begin{tabular}{|c|c|c|c|c|c|}
\hline & Sum of Squares & Df & Mean Square & F & Sig. \\
\hline Between Groups & 4248.938 & 2 & 2124.469 & 5.018 & .014 \\
\hline Within Groups & 11430.079 & 27 & 423.336 & & \\
\hline Total & 15679.017 & 29 & & & \\
\hline
\end{tabular}

* Significance difference at $p<0.05 \%$ 
TABLE (7) Comparison between different studied groups as regard tensile bond strength using Post Hoc test (LSD) after short-term water storage and thermo-dynamic stressing

\begin{tabular}{|c|c|c|c|c|c|c|}
\hline (I) Factor & J) factor) & $\begin{array}{c}\text { Mean } \\
\text { Difference (I-J) }\end{array}$ & Std. Error & \multicolumn{2}{|c|}{ Sig. } & \multicolumn{2}{|c|}{$95 \%$ Confidence Interval } \\
\hline Provilat cement & Rely x Temp & 21.7818 & 9.2015 & $(*) .025$ & 2.9019 & 40.6617 \\
\hline & Cavex Temp & 27.6690 & 9.2015 & $(*) .006$ & 8.7891 & 46.5489 \\
\hline Rely x Temp & Provilat cement & 21.7818 & 9.2015 & $(*) .025$ & -40.6617 & -2.9019 \\
\hline Cavex Temp & Provilat cement & 27.6690 & 9.2015 & $(*) .006$ & -46.5489 & -8.7891 \\
\hline & Rely x Temp & 5.8872 & 9.2015 & .528 & -24.7671 & 12.9927 \\
\hline
\end{tabular}

* Significant difference at $\mathrm{P}<.05 \%$.

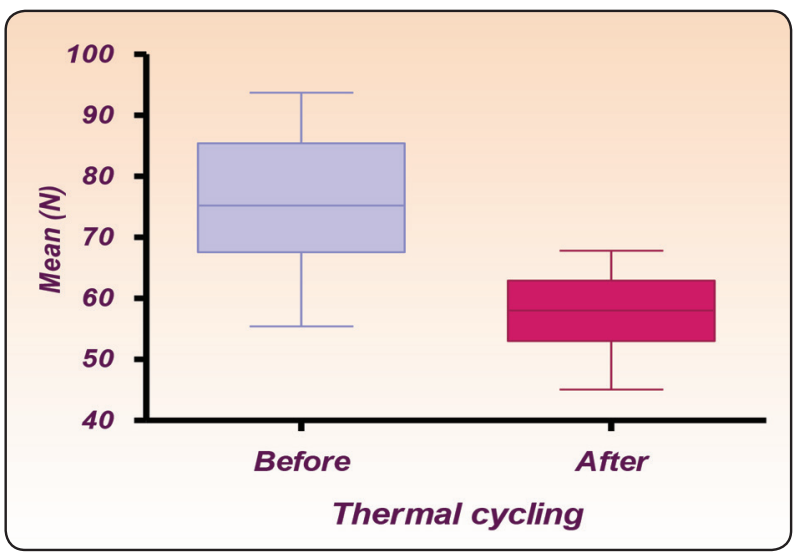

Fig. (1) A box plot of retention mean values as a function of thermocycling.

\section{DISCUSSION}

Cement type in addition to the abutment height, width, and diameter have been reported to influence the retention of cement-retained restorations ${ }^{[5]}$. Maxwell et al. ${ }^{[23]}$ examined the effect of the crown preparation height on the retention of gold castings and reported that the retentive force of an abutment height of $3 \mathrm{~mm}$ was decreased by half compared with that of an abutment height of $5 \mathrm{~mm}$. Therefore, the abutments dimensions used in the current study were standardized as $5.5 \mathrm{~mm}$ length, $3.5 \mathrm{~mm}$ diameter and $5^{\circ}$ taper.

Some specimens were subjected to mechanical loading and thermocycling. The establishment of in vitro methodologies simulating oral conditions constitutes important means of evaluating the clinical potential of dental materials ${ }^{[24]}$. The reduction in bond strength after water storage and thermodynamic stressing (subgroups A2, B2, C2) could be attributed to that the thermal cycling induced stresses as a result of differences in coefficients of thermal expansion. Flaws caused by thermal stresses might result in damage that led to crack initiation and propagation at the bonding interface ${ }^{[25]}$.

In the present study, a variation was found in the retention values for each group. This indicates that the commercially available brands have different physical properties which might be due to the different compositions of the evaluated interim luting cements (non-eugenol containing zinc oxide and calcium hydroxide). The results of this study are in accordance with the findings of other previous studies ${ }^{[26-27]}$ in which the Dycal interim luting cement (which has the same composition of 
Provilate cement) showed higher retentive values, with statistically significant difference $(p<0.05)$ when compared to Temp Bond NE (which has the same composition of RelyX Temp NE cement and Cavex Temp NE cement), yet with no statistical difference when comparison was made among noneugenol cements.

The results of the present study were in disagreement with another study [28] which found that Temp Bond NE (which has the same composition of RelyX Temp NE cement and Cavex Temp NE cement) showed similar retentive results when compared to calcium hydroxide cement. The difference between our results and that study could be due to absence of thermodynamic cycling in that study.

In the present study, all specimens showed adhesive form of failure. This is in accordance with the finding of Dudley et al. ${ }^{[13]}$ who stated that air abraded copings and abutments had better micromechanical retention than smooth titanium abutments which make the cement adhere to the abutments. The results of the present study are also in agreement with previous work by Mansour et al. ${ }^{[29]}$ who examined the retention of six cements for metal copings on ITI solid titanium abutments, the unaltered smooth machined abutment surface could have decreased the cementabutment micromechanical interlocking, leading to comparatively decreased cement retention values.

Most luting cements used in implant dentistry today were originally developed for use with natural teeth. Cementing crowns to natural teeth mainly depends on some degree of chemical bonding to natural tooth structure. In contrast, the use of most dental cements with implant components largely lacks this potential for chemical bonding. Some resin cements have developed the potential to bond to metal surfaces to aid in the enhancement of retention for cemented implant crowns. Still, they are considered permanent luting cements. The mode of cement failure in this study appeared directly related to the greater physical retention provided by the two opposing surfaces the cement separates.

Other limitations of the study may include that it is an in vitro study and conditions that may affect the bond strength in vivo were not all tested. For example, the effects of fluctuating $\mathrm{pH}$, magnitude and direction of force as would be observed in the oral cavity, were not evaluated in this study.

\section{CONCLUSIONS}

Within the limitations of this in vitro study, it can be concluded that copings cemented with Provilat cement had the highest results when compared to those cemented with the other tested interim cements (RelyX temp cement and Cavex temp Cement). Calcium hydroxide based provisional luting agent seems to be more appropriate for the cementation of implant supported restoration, if retrievability is important. Short-term water storage and thermodynamic stressing significantly decreased the bond strength regardless of the type of cement used.

\section{REFERENCES}

1. Zarb GA, Schmitt A. The edentulous predicament II: the longitudinal effectiveness of implant-supported overdentures. Jam Dent Assoc 1996;127:66-72.

2. Hebel KS, Gajjar RC. Cement-retained versus screwretained implant restorations: Achieving optimal occlusion and esthetics in implant dentistry. J Prosthet Dent 1997; 77: 28-35.

3. Sheets JL, Wilcox C, Wilwerding T. Cement selection for cement-retained crown technique with dental implants. J Prosthodont 2008; 17: 92-6.

4. Breeding LC, Dixon DL, Bogacki MT, Tietge JD . Use of luting agents with an implant system: Part I. J Prosthet Dent 1992; 68: 737-41.

5. Bernal G, Okamura M, Munoz CA. The effects of abutment taper, length and cement type on resistance to dislodgement of cement-retained, implant-supported restorations. J Prosthodont.2003; 12:111-5. 
6. Pauletto N, Lahiffe BJ, Walton JN. Complications associated with excess cement around crown on osseointegrated implants: a clinical report. Int J Oral Maxillofacial Implants 1999; 14:865- 8.

7. Agar JR, Cameron, SM, Hughbanks JC, Parker MH. Cement removal from restorations luted to titanium abutments with simulated subgingival margins.J Prothet Dent 1997;78:43-7.

8. Armellini MS, Bilko RD, Carmichael DM, Von Fraunhofer JA. Screw- retained prosthesis for Straumann implant sites with limited interocclusal clearance. J Prosthodont 2006; 15:198-201.

9. GaRey DJ, Tjan AH, James RA, Caputo AA. Effects of thermo cycling, load-cycling, and blood contamination on cemented implant abutments. J Prosthet Dent 1994; 71: 124-32.

10. Spear F. Connecting teeth to implant the truth about debated technique .J.Am Dent Assoc 2009; 140: 587-93.

11. Sadaqah N, Wahadni A, Alhaija E. Implant abutment types: literature review I. Eur J Oral Sci 2010; 2:75-80.

12. University of Michigan. Biomaterials Properties Database. (April 1996). Available from: http://www.lib.umich.edu/ dentlib/Dental_tables (Accessed 6 April 2006).

13. Dudley JE, Richards LC, Abbott JR. Retention of cast crown copings cemented to implant abutment. Australian Dental Journal 2008; 53: 332-9.

14. Jacob SJ, Hegde C, Prasad KD, Shetty M. An in vitro study to evaluate the effect of storage time and application of subsequent layers onthe variation in thickness of three commercially available die spacers .Indian J Dent Res 2010; $21: 92-7$

15. Mehl C, Harder S, Steiner M, Vollrath O, Kern M. Influence of cement film thickness on the retention of implant-retained crowns.J Prosthodont 2013; 22: 618-25.

16. Saleh Saber F, Abolfazli N, Nuroloyuni S, Khodabakhsh S, Bahrami M, Nahidi R, et al. Effect of Abutment Height on Retention of Single Cement-retained, Wide- and Narrowplatform Implant-supported Restorations. J Res Clin Dent Prospects2012; 6:98-102.

17. Lee HY, Lee HS. In vitro study of the tensile bond strength of cement-retained single implant prosthesis by the various provisional luting cements and the surface treatment of abutments. J Korean Acad Prosthodont 2002; 40:296-305.
18. Al Hammad KQ, Al Rashdan BA, Abu-Sitta EH. The effects of height and surface roughness of abutments and the type of cement on bond strength of cement-retained implant restorations. Clin Oral Implants Res 2011; 22:638-44.

19. Valbao FP, Perez EG, Breda M. Alternative method forretention and removal of cement-retained implant prostheses. J ProsthetDent 2001; 86:181-3.

20. Guilherme M, Pisani J, Carolina M, Spielmann C, Castillo RD. Effect of two axial wall height preparations on the retentive properties of full crowns using three different cements J Gen Dent 2008; 56:569-573.

21. Krejci I, Lutz F, Reimer M. Marginal adaptation and fit of adhesive ceramic inlays. J Dent1993; 21: 39-46.

22. Jemt T, Karlsson S, Hedegard B. Mandibular movement in young adults recorded by internally placed light-emitting diode. J Prosthet Dent 1979; 42: 669-73.

23. Maxwell AW, Blank LW, Pelleu GB, Jr. Effect of crown preparation height on the retention and resistance of gold castings. Gen Dent 1990; 38: 200-2.

24. Cunha Mello FS, Feilzer AJ, Gee AJ, Davidson CL. Sealing ability of eight resin bonding systems in a Class II restoration after mechanical fatiguing. J Dent Mat 1997; 13: $372-6$.

25. Amano S, Yamamoto A, Tsubota K. Effect of thermal cycling on enamel bond strength of single-step, self-etch systems. Oper Dent 2006; 31: 616-22,

26. Dong-Hee Lee, Kyu-Won Suh, Jae-Jun Ryu. Comprison of retentive forces of temporary cements and abutment height used with implant- supported restorations. J Kor Acad Prosthodont 2008; 43:280-9.

27. Ishikiriama A, Busato ALS, Navarro MFL, Mondelli J. Temporary cementation of acrylic resin and cast complete crowns. J Prosthet Dent 1984; 51: 637-41.

28. Lepe X, Bales DJ, Johnson GH. Retention of provisional crownsfabricated from two materials with the use of four temporary cements. J Prosthet Dent 1999; 81: 469-75.

29. Mansour A, Ercoli C, Graser G, Tallents R, Moss M. Comparative evaluation of casting retention using the ITI solid abutment with six cements. Clin Oral Impl Res 2002; 13: $343-8$. 